JACQUES LE BOURGEOIS

SANTIAGO, CHILE

LEBOURGEOIS.JACQUES49@GMAIL.COM

TRADUCCIÓN: SANDRA VALDERRAMA
1. Este artículo es un extracto de su tesis de doctorado en Historia.

Fecha de recepción: 28/06/2017

Fecha de aceptación: 08/11/2017

Cómo citar: Le Bourgeois, J. (2017). El cartel

político soviético, una especificidad. RChD:

creación y pensamiento, 2(3), 1-9.

DOI: 10.5354/0719-837X.2017.47696

\section{El cartel político soviético, una especificidad ${ }^{\mathbf{1}}$}

The soviet propaganda poster: A specificity

Resumen. El autor del artículo, (extracto de su tesis de doctorado de Historia), propone un acercamiento específico al afiche de propaganda soviética. Son productos característicos de la cultura rusa, inspirados en los íconos y las tradiciones pictóricas rusas como el "lubok". El arte del cartel será también parte de una formación artística específica, ramo de la Academia de Bellas Artes. La mayoría de ellos son obras de arte, pero tienen como esencia la difusión de la ideología. Y su originalidad está justamente en lo que el autor califica como consubstancialidad, usando una palabra del campo religioso para definir esta mezcla inalterable artística y política que caracteriza el cartel soviético. Eso podría explicar su atracción actual, la pasión de algunos coleccionistas y el permanente cuidado que observa el Estado ruso hacia ellos. Los afiches analizados (un corpus de más de 3500 piezas) pertenecen principalmente a tres centros ubicados en Moscú: el Museo de las Fuerzas Armadas rusas, la Biblioteca Nacional, Ilamada Lenin y el Centro de Archivo Nacional ruso de literatura y arte (Archivo de Literatura y Arte del Estado de Rusia, RGALI). Palabras clave: afiche político, afiche político soviético, arte y política, arte e ideología, propaganda soviética.

\begin{abstract}
The author of the article, (extracted from his doctorate thesis in History), suggests to us an original approach of the Soviet propaganda poster. They are characteristic products of Russian culture, rooted in icons and popular pictorial traditions such as the Lubok. The art of the poster is also part of a specific artistic training, a branch of the National Fine Arts and Architecture Academy. A lot of them are really works of art, but they mainly serve to the diffusion of ideology. And their originality is precisely located in what the author calls consubstantiality, using a religious word to define this immutable mixture of art and ideology which characterizes the Soviet poster. This would explain their current attraction, the passion of collectors and the continuous attention of the Russian state upon them. The posters analyzed, (a collection of more than 3500 pieces), mainly belong to three centers situated in Moscow: The Museum of the Russian Armed Forces, the Lenin National Library and the Center of National Russian Archives of Literature and Art (RGALI).
\end{abstract}

Keywords: art and ideology, art and politics, political poster, soviet political poster, soviet propaganda. 
1. La era soviética comienza con la Revolución

bolchevique del 25 de octubre de 1917 (calendario juliano) y termina con la dimisión de Gorbachov el 25 de diciembre de 1991, el desmantelamiento de la uRSS y la creación de la República Federal de Rusia. La diferencia entre los calendarios juliano y gregoriano es de 13 días y el pasaje del uno al otro será decidido el 31 de enero de 1918.

2. Nina Baburina, socióloga e historiadora rusa contemporánea, es la autora de la obra más completa sobre los afiches soviéticos, Sovietski polititcheski plakat, Leningrad, 1984.

3. Gueorgui Plekhanov fue uno de los fundadores del movimiento marxista ruso, socialdemócrata. Exiliado durante 40 años, apoyó a la Revolución de 1905, pero será crítico de la de 1917. Tuvo relaciones difíciles con Lenin, aun siendo su mentor.

4. Viatcheslav Polonski, autor de Ruski revoliutsioni plakat, Moscú, 1925, era el primer dirigente del litizdat, editorial del Servicio Político Militar, PUR, creado en 1919.
Los carteles de propaganda política soviética han desempeñado un papel importantísimo como elemento de agitación política que, en un comienzo, ni siquiera los bolcheviques imaginaron, y que sus sucesivos dirigentes soviéticos no dejaron de perpetuar. Lo que es destacable es su longevidad, 74 años, desde la Revolución bolchevique de 1917 hasta la caída de la Unión Soviética en 1991; su profusa producción, 55 mil ejemplares es la cifra entregada por Nina Baburina (1984)², especialista en el campo; incluso, otros expertos indican que son millones. Igualmente impresionante es su fuerza de atracción, la captura del público, y su poder de persuasión. Así de sorprendente es el interés que este medio de propaganda despertó y que, por cuya naturaleza ambigua, incita a la prudencia o bien a la desconfianza; a pesar de que levante las pasiones de historiadores, coleccionistas y estetas.

¿Podemos hablar de especificidad? Algunos propondrán la idea del Arte totalitario, sin duda verídico, al referirse a ciertos períodos, pero no todos; ciertamente el arte de las masas. Los bolcheviques crearon un medio de agitación política, “Un solo mensaje dirigido a las masas”, como lo especifica Gueorgui Plekhanov 3 en su Marxismo militante. Pero se conservará una fórmula, la de Polonski (1925) ${ }^{4}$, el primer responsable del LITIZDAT. Él lo describe con exactitud: “Es el Arte que ha bajado a las calles!”. El arte que hasta ese momento estaba reservado a los estratos ricos de la sociedad zarista se dirige al pueblo. Y eso no es todo, puesto que, en aquellos años revolucionarios marcados por una exuberancia, una ebullición de ideas, un fulgor de imágenes, artistas de renombre tales como Chagall, Malevitch, Lissitski, Maïakovski, han sido parte de aquello. Estas personalidades del mundo artístico, comprometidos con el combate político, van a conferir a los carteles una dimensión y una reputación internacional duraderas. EI arte se compromete con la política. Se impregna de la política a tal punto de ser uno con la ideología que sostiene. Los dos son indisociables. En este estadio, se propone la idea de consustancialidad, término prestado del campo religioso para significar la alianza de lo divino con lo carnal, y que conviene perfectamente aquí. Ya no se trata solamente del intelecto preocupado de la palabra y la idea, ni de ser afectados emocionalmente por el diseño, la emoción y el sentimiento liberados, sino el imaginario y lo sobrenatural, la proyección en una perspectiva universal y cósmica. El hombre se convierte en un semidiós. La utopía no es más del orden de un futuro posible sino de una realidad que podemos tocar con un dedo, como decía Máximo Gorki. El constructivismo y el realismo socialista, los hermanos enemigos a los ojos de los dirigentes, son los ejemplos más característicos. De hecho, existen dos grandes tipos de carteles, el estaliniano y el constructivista, representantes de la tipología soviética. Aunque esta aseveración es pertinente, no es suficiente; ya que estos dos afiches solo cubren dos períodos, ciertamente extensos, pero no únicos. Hubo otros y muchos. Nos hace falta entonces investigar en otro lugar los criterios de esta especificidad.

Esto se debe principalmente a tres factores: el legado ruso que marca sus orígenes, la institucionalización de un género con la creación de una escuela de cartelistas, y ante todo, la consustancialidad del arte con la política que no se encuentra en ningún otro sitio, al menos de una manera tan marcada, así como duradera y también de una gran calidad estética. 


\section{El legado ruso}

Si los bolcheviques no fueron los inventores del cartel, como lo escribe Kenez (1985) sí fueron los innovadores en su utilización y la magnitud que le otorgaron. Sin embargo, a principios del régimen, el arte del afiche ocupaba solo un tercer rango en las artes, por debajo de la arquitectura y la industria del cine, como lo precisaba el decreto de las artes de 1918. Es solo en la primavera de 1918, siete meses después de la Revolución de Octubre en que se supone aparecen los primeros carteles. Primero, se erigieron unos monumentos, aunque no siempre exitosos, para contrarrestar la proliferación de aquellos dedicados al antiguo régimen, principalmente del zar. Luego, poco a poco, se organizaron los órganos de propaganda y de edición, y la producción no dejará de crecer y desarrollarse en una variedad de estilos exuberantes (el vanguardismo, el arte abstracto, el realismo, el constructivismo) y otros géneros (la alegoría, el simbolismo, los “luboks”, las caricaturas satíricas, el fotomontaje e ilustraciones dramáticas). Marc Ferro (1982) habla de genialidad exuberante. ${ }^{5}$ En cuanto a Denisovsky (1970, pp. 17-19), autor de una de las primeras obras consagradas al cartel, lo define: "Nuestros pinceles y nuestros lápices son nuestras armas", 6 retomando así la fórmula de Maïakovski. Al menos por el período revolucionario, los historiadores concuerdan en un número cercano a los 3.500 carteles.

Sus orígenes son efectivamente particulares a la cultura rusa, y su característica mayor es el "lubok", una especie de sátira cómica de origen popular que remonta al siglo XVI. Arte tradicional que consistía en unas pinturas sobre madera hechas por campesinos, representaciones de índole aldeana o religiosa. En el siglo XVIII, este arte tomó poco a poco una dimensión política bajo la forma de dibujos satíricos, como la ilustración anónima, "Los ratones sepultan al gato", donde el Zar Pedro el Grande, según ciertas interpretaciones, sería el gato, sepultado por el pueblo retratado como ratones. En el siglo XIX este aspecto político se confirma a través de pinturas satíricas de la campaña napoleónica. Durante la Primera Guerra Mundial, se crea un taller, "el lubok contemporáneo" en el cual participan artistas de renombre a quienes encontraremos durante el período revolucionario, como Kasimir Malevich, fundador del suprematismo, y Vladimir Maïakovski, creador del movimiento de los poetas futuristas. El vínculo está allí y se encuentra mediante un sin fin de carteles de tipo "lubok" como "La baba rusa rechazando al enemigo", "El nuevo calendario" de Maïakovski, entre otros, y un gran número de carteles de la agencia Rosta.7 No obstante, el estilo fue muy controvertido. Los partidarios del carácter innovador y revolucionario de la doctrina verán allí la obsolescencia e ingenuidad a la que combatían, incluidos aquellos quienes afirmaban hacer arte por el arte según la línea de los pintores ambulantes. En cuanto a los realistas, ellos se oponían abiertamente. Pero los que entendían la necesidad de ir hacia el pueblo, de hacerse comprender, lo utilizarán en sus fines propagandísticos. La línea de división entre los dos está lejos de estar claramente definida, y es lo que explicaría su desaparición esporádica, pero también su resurgimiento. Así, el “lubok” reaparece durante la Gran Guerra Patria, luego se engalana de una manera más moderna durante la Perestroika. La composición de un gran cartel constituido de varios elementos no es más que la prolongación de este género que se decía anticuado. De hecho, es el político quien deberá decidir más que el artista.
5. Marc Ferro, historiador francés, escribió:

"Deslumbrantes años de ilusión, de esperanza y de tragedia", en "Carteles e imaginería rusas 1914-1921", Museo de las Guerras Mundiales, París, BDIC, 1982.

6. Denisovski N., Okhno Tass, 1941-1945, Izdatielstvo Iskusstvo, Moscú, 1970.

7. Rosta, agencia de información telegráfica soviética. Durante la guerra civil, se crea un taller llamado “Okhno Rosta”, encargado de producir carteles de propaganda política. En 1925, Rosta es reestructurado y se convierte en TASS. $Y$ durante la Gran Guerra Patria, se crea en su seno un nuevo taller, TASS Okhno, con la misma finalidad que Rosta Okhno. 


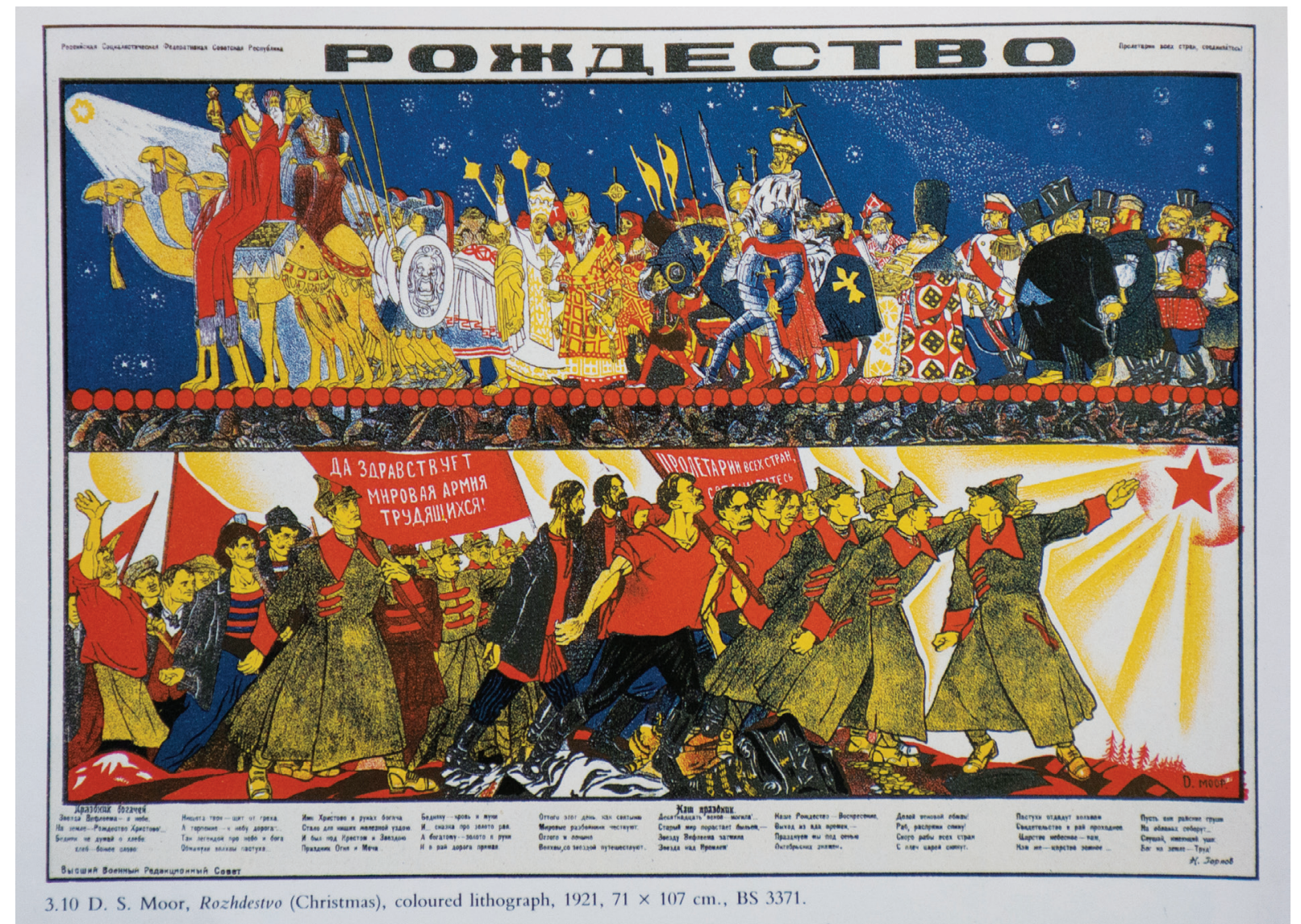

Figura 1. "Navidad", D. S. Moor, 1921. Fuente: Biblioteca Lenin.

8. "Sin dios".
El otro origen es el ícono. El arte religioso, venido con el cristianismo hacia los años mil, es un tema controvertido. A este se oponen por principio los partidarios de la tesis marxista; otros reducen su influencia. Sin embargo, un pintor como Moor, militante ateo y fundador del periódico Biezbojnik, ${ }^{8}$ reconocerá en sus memorias haberse inspirado por el ícono y apreciado sus calidades artísticas. Otros artistas convienen en decir que el ícono otorgó una fuerte influencia, aun cuando a semejanza de Irene Semenoff Tian Chansky, la ejecución de un ícono debía responder a los cánones artísticos, comenzando por el ayuno ascético que los pintores de afiches de propaganda probablemente no observaban. Sin embargo, los rastros de una influencia son evidentes. La utilización de códigos de color: el rojo de los santos es retomado para representar a los héroes; el negro, retratando al demonio, el color del enemigo, del capitalismo y del fascista. Los símbolos son tan idénticos. El dragón, símbolo del mal en la imagen piadosa, se convierte en la representación del enemigo. Se utilizará también la composición en tríptico a semejanza de los carteles que marcaron la victoria de 1945 hasta su última aparición en 1985 . O aún las imágenes de la trinidad representadas por los rostros notables de la contrarrevolución. Así como la imagen de San Jorge, derrotando al dragón del imperialismo, recobra curiosamente los rasgos de Trotsky. Y esto, sin tomar en cuenta la desnaturalización de las imágenes piadosas con el fin de desacreditar la religión, puesto que eso era una temática combatida constantemente por la propaganda. 
Ahora bien, el ícono reaparecerá en su forma original durante la Perestroika para entregar un retrato modernista de un Cristo que se titulará “ $\mathrm{iNo}$ matarás!"; o bien, el cartel dedicado a Alejandro Newsky, los dos homologados por el servicio de propaganda oficial.

El tercer criterio es suministrado por la tradición de los periódicos satíricos. Esta clase de publicaciones proliferaba en la época zarista, sobre todo después del levantamiento de 1905. El factor común entre estos periódicos y los carteles es la caricatura, obra de pintores de los cuales reencontramos la firma debajo de los carteles. Vladimir Kozlinsky, Vladimir Lebedev, y Maïakovski han colaborado con estos periódicos, el Satirikon y el Novyi Satirikon. Victor Deni, autor de carteles brillantes durante el período revolucionario como "Capital", y luego, durante la Gran Guerra Patria con "Stalingrad", colaboraba con el Boudilnik.

El cuarto criterio es el cartel publicitario. Más reciente que los demás, este arte aparecerá solo a finales del siglo XIX con la industrialización naciente de la Rusia zarista, inspirándose en lo que se hacía en Occidente, y en particular, en los Estados Unidos y en Europa occidental. Polonsky (en Butnik Siversky, 1960, p. 4). no dudará en hablar de "una continuación entre el cartel publicitario zarista ruso y los primeros carteles de propaganda política bolchevique". Si bien este aspecto es menoscabado, incluso ocultado por el régimen, a raíz de sus orígenes 'burgueses', no es un impedimento para que un artista como Maïakovski pasara del cartel político al afiche comercial durante la NEP, ${ }^{9}$ considerando que la promoción de su producto no podía hacerse sin las armas del adversario.

Finalmente, podemos solo constatar una real continuidad entre los carteles de la propaganda política zarista y aquellos del régimen de Kerensky con el bolchevique. A semejanza de lo que los regímenes occidentales practicaban durante la Primera Guerra mundial, el zarista había creado su propio organismo de propaganda, el osWAG, ${ }^{10}$ cuyos carteles no solo irían a servir de modelo, pero serían copiados por los servicios de propaganda bolchevique. Fue el caso del cartel de Pasternak, "Por la sangre derramada", luego aquel anónimo, consagrado al "Préstamo de la libertad" o aun aquel hecho para la organización de la "Asamblea Constituyente". El legado ruso es innegable, fundamental y evidente, a pesar de algunas prohibiciones u omisiones. Sin embargo, este no estará exento de ciertas influencias extranjeras, empezando por el dedo del cartel británico de Kitchner; ${ }^{11}$ incluso aquella de la escuela polonesa en el transcurso de la Guerra Fría, pero esto será puntual. Esta particularidad es la marca viviente de una cultura antigua que se perpetuará en el arte del cartel y que va a perdurar todos estos años.

\section{La institucionalización de un género}

El rol del cartel en la propaganda soviética reviste tal importancia que se institucionalizó desde 1927. Se trata de promover un género, un estilo y de perpetuar un saber hacer dentro de una formación artística específica y de calidad. Ya sea que los pioneros hayan sido solicitados o voluntarios persiguiendo sus propias actividades, ellos fundaron los talleres o clubes (Rosta Okhno, aquel de los futuristas) y las escuelas (Vitebsk y el grupo de los constructivistas). Así, según las fuentes del RGALI, ${ }^{12}$ existían a mediados de los años veinte más de catorce talleres especializados solo en la ciudad de Moscú. En 1922, los cartelistas constatan la necesidad de reagruparse en la Asociación de Artistas Revolucionarios. Estamos todavía en la etapa del amateurismo o del aficionado.
9. NEP (Nueva Política Económica), iniciada por Lenin en 1921, esta nueva orientación política era una tregua en materia de colectivización y nacionalización. Su objetivo era impulsar la economía debilitada por los años de guerra. Permitió el pequeño comercio, el artesanado y la pequeña propiedad privada. Será prohibida en 1929 con la llegada al poder de Stalin y el lanzamiento de la colectivización forzada y la industrialización pesada.

10. OSWAG, organismo de inteligencia militar zarista.

11. El afiche de Kitchner fue editado en Gran Bretaña durante la Guerra de los Boers. El dedo de Kitchner llamaba al reclutamiento, que servirá más tarde de modelo al del tío Sam, "I want you!".

12. RGALI, Archivo Estatal Ruso de Literatura y Arte. Nombre adoptado en 1992; tuvo otros anteriores. 
Figura 2. "Joven Fritz", Kukrynskii, Okhno Tass

$n^{\circ} 307,1941$. Fuente: Museo de la Fuerzas Armadas Rusas de Moscú.

13. Vkhutemas (instituto Superior Nacional Artístico y Técnico) creado en 1920 para reemplazar los antiguos institutos zaristas. Su sigla cambiará en el transcurso de los años siguientes, antes de retomar la denominación antigua después de la guerra: Surikov en Moscú, y Repine en Leningrado, siempre vigente.

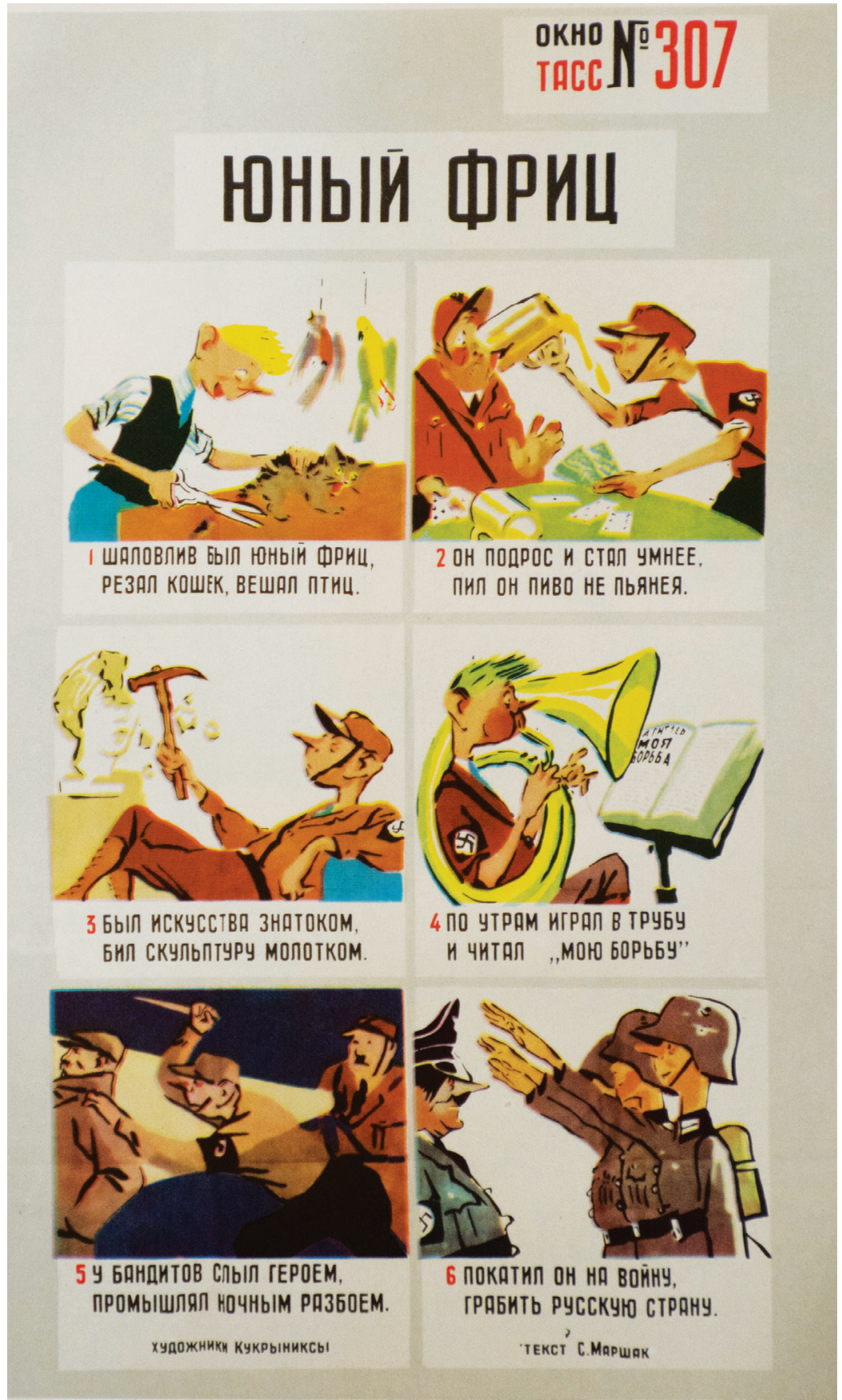

Pero en 1927, se establece el ramo del cartel en el seno de los Vkhutemas. ${ }^{13}$ El género del cartel se institucionaliza. Y sus primeros profesores serán Moor, Favinski y Vivinski, todos ellos comprometidos con el cartel revolucionario. En el mismo año, se crea el Gabinete de la enseñanza del arte de la agitación y de la propaganda en el seno de la Academia de las Ciencias y del Arte de Leningrado. En 1947, se convertirá en una sección de la Academia de Bellas Artes de la Unión Soviética. Este hecho es importante puesto 


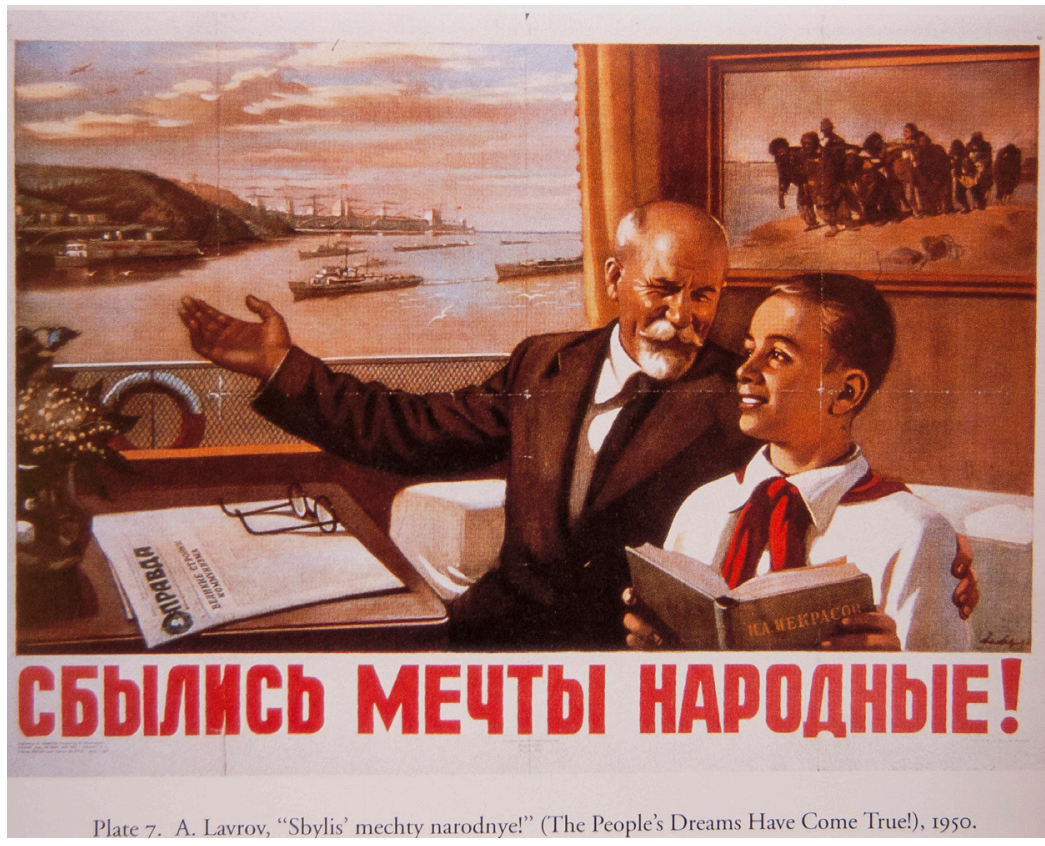

que la Academia ejercía un rol fundamental en materia de instrucción y control. Es ella quien fija los estándares estéticos, quien interviene en tanto a los artistas los protege al mismo tiempo que los controla.

Paralelamente a esta organización estructural, se constituyen las asociaciones artísticas. El 23 de mayo de 1931 se crea la ORRP (Organización de Trabajadores Revolucionarios del Cartel) que integra la Federación Soviética de Artistas, la FORSPI. La rama de Moscú integra la Unión de Artistas de Moscú, la MOSKH ${ }^{14}$ puerta obligada para todo cartelista que pretenda ser considerado para un concurso de carteles de propaganda. Estos organismos sufrirán algunas modificaciones dentro de sus estructuras y denominaciones, pero las funciones permanecerán. $Y$ todo artista propagandista debía haber recibido su sello blanco para poder ejercer su arte.

Pero esta institucionalización va también a marcar el fin del vanguardismo y consagrará un estilo. El realismo socialista es oficializado en 1934. El vanguardismo y el constructivismo serán considerados como incomprendidos por el pueblo, ante lo cual el sindicato de escritores recomienda el realismo socialista, que se convertirá en el arte oficial de todas las otras disciplinas artísticas por decreto. Ideinost, ${ }^{15}$ Narodnost, ${ }^{16}$ Klassnot $^{17}$ son los tres criterios que lo definen. Se va a imponer en los carteles hasta la Perestroika, aunque cohabitará con los otros géneros en particular durante la Gran Guerra Patria y durante la Guerra Fría, especialmente en los años sesenta, período de deshielo ${ }^{18}$ hasta el fin de régimen de Khrushchev.

Así, representado por un estilo, consagrado por una escuela, obras de artistas especialistas del género, el cartel de propaganda soviético constituye un dominio específico e institucional del arte que las autoridades se esforzaron por preservar. Prontamente, se decide conservar las copias en archivos. ${ }^{19}$ Resguardados en los museos, los carteles son presentados, con regularidad, al público en ocasión de eventos conmemorativos tanto en la Unión Soviética como en el extranjero.
Figura 3. "Los sueños se hicieron realidad", Lavrov, 1950. Fuente: Museo de la Fuerzas Armadas Rusas de Moscú.

14. MOSKH (Unión de los Artistas de Moscú) creada en 1932.

15. Reflejo de una ideología.

16. Reflejo del pueblo.

17. Reflejo de una clase, en particular, la clase proletaria.

18. El período de deshielo se ubica entre 1956 , fecha de la denuncia de los crímenes de Stalin por Khrushchev y 1962, con el caso del "Manège". El 2 de diciembre de 1962, Khrushchev visita una exposición organizada por pintores anti conformistas con la autorización del sindicato de los artistas. Las pinturas no le gustaron a Krushchev, por lo que se enfureció y lo que le hizo decir: “¡En el Arte, soy estalinista!”. La exposición será cerrada y prohibida.

19. Retomando las directivas zaristas, el régimen 7 bolchevique decide en 1918 guardar tres copias de cada obra. Esas copias son archivos que se encuentran ahora en los centros de archivos, principalmente en la Biblioteca Nacional, Lenin. 
20. Y premiado. Recibirá una medalla de plata por su obra.

21. Perestroika significa "reconstrucción" y Glasnost "transparencia".

\section{La consustancialidad del arte con la política}

Como se ha señalado anteriormente, este término ha sido originario del campo religioso, y que define el vínculo entre lo divino y lo carnal para aplicarlo a los carteles soviéticos, puesto que ellos representan, el ejemplo característico de la fusión entre el arte y la política. El arte, a través de un esteticismo, a menudo de gran calidad, es impregnado de política y está, en su noción más penetrante, sublimada por el primero. De hecho, más que de política, convendría aquí hablar de ideología. Este es el aspecto que distingue los carteles soviéticos de propaganda de todo lo demás.

En esta fase, se podría argumentar legítimamente que, si bien el constructivismo y el realismo socialista son los mejores exponentes del período soviético, estos no son los únicos estilos dentro del conjunto.

El constructivismo soviético de los años veinte y treinta se inspira en el constructivismo occidental. Sus formaciones geométricas, sus puestas en perspectiva desestabilizante estaban allí para magnificar este nuevo mundo, esta sociedad moderna surgida después de un largo período de obscurantismo. Sin embargo, los pintores bolcheviques, y luego soviéticos, le han dado un toque particular. Han introducido un hombre, y lo han transformado en superhombre, un poco al estilo de Nietzsche. Una especie de semidiós que domina este modernismo, construido por él y para él. El constructivismo era ya la utopía. Durante la exposición de París de 1925 de la cual Maïakovski será participante,,$^{20}$ los críticos sabrán reconocer esta particularidad. El ideal de un hombre nuevo es palpable en los carteles soviéticos. El problema es que, en la Unión Soviética, este estilo no era popular; muy moderno, muy abstracto y demasiado frío, e insuficientemente humano. Preferían al realismo socialista. La sociedad había cambiado, los gustos también. En 1934, será reconocido como el único arte oficial.

Con el realismo socialista una vez más se reivindica la utopía. Aunque esta vez representa lo animado, la alegría de vivir, la exaltación y el sueño. La ideología, prometiendo la futura felicidad socialista, se reencontró perfectamente en este género, como si estuviera hecho para ella. En los años treinta, aunque son tiempos difíciles, los carteles se pueblan de gente radiante. Aquellos de los años cincuenta afirman que los sueños se han hecho realidad. Y con la victoria de 1945, todos son tentados de creerles. Es evidente que, para los extranjeros, estas afirmaciones eran difícilmente admisibles. Pero, para los soviéticos, por fe, convicción, y también por temor, les era bastante plausible. No se contentaba solo con ver, se creía. ¡Es el milagro de este estilo! Mientras tanto las revelaciones de los crímenes de Stalin tendrán un fuerte impacto a esta admiración. Sin embargo, este estilo va a continuar imponiéndose hasta el año 1988. E incluso, mientras es denigrado, y el cartel sugiere la duda del pintor, el "rendu" artístico entrega un nuevo estilo; tan emocionante como el primero, tan poderoso, pero más austero, más frío, es el realismo severo o también, avatar de esta época, el SocArt, réplica soviética del Pop Art occidental. Allí, aún los carteles atrapan al lector, ya que interpelan en lo más profundo de uno, ellos llegan a la más mínima fibra de nuestro afecto y nuestro imaginario.

Además, cuando finalmente interviene la Perestroika, más específicamente la "Glasnost", ${ }^{21}$ con su transparencia y su pluralismo -mientras finalmente el realismo socialista es destituido de su monopolio, mientras la ideología 
misma es replanteada-, los carteles, en su exuberancia loca, sin riendas, en un exhibicionismo desorientado, hacen alarde del fracaso del régimen y del malestar social. Ellos interpelan, provocan y agreden con una fuerza desconcertante. Ellos atacan los viejos demonios y traen otros nuevos, como si mientras un capítulo de historia venía de cerrarse, uno nuevo se perfilaba. Cargados de dolor y esperanza, ellos dejaban al público en el caos, a medio camino entre la sonrisa de conveniencia y la inquietud frente al futuro. Este no es más radiante, incluso menos seguro. Los carteles de la Perestroika ponen al soviético delante de su destino. Es una vez más una relación cosmogónica que se transmitirá en el arte; entre lo sobrenatural y lo carnal la pared es delgada. El arte se impregna de política, se nutre de ella y la expresa como si los dos fueran uno solo. Y esto es lo que se refleja en los carteles. Son estas características, el legado ruso, la institucionalización del género y la consustancialidad del arte con la política, lo que hace que el cartel de propaganda soviético sea único. Existen otros con similares rasgos iconográficos, los símbolos, pero creo que no hacen más que confirmar aquello. Estos serán reutilizados por otros, en particular, los partidos políticos comunistas del mundo entero. En cuanto a lo primero, por qué se suscribe a la cultura rusa, no podía ser asimilado sino solo por los rusos mismos. Muchas editoriales rusas hacen un comercio lucrativo de esto, puesto que el cartel soviético se transformó en un producto de valor y las colecciones se multiplican, señal del interés alcanzado.

\section{Bibliografía}

Baburina, N. (1984). Sovietski polititcheski plakat. Leningrad.

Barkhtova E.V. (2005). Konstruktivism v sovietskom plakatie. Moscú: Kontakt Kultura editores.

Butnik Siversky, V.S. (1960). Sovietsky plakat 1918-1921, epokhi grajdanskoe voïny. Moscú: Vsiesoiuznoi knijnoi plakaty.

Denisovski N. (1970). Okhno Tass, 1941-1945. Moscú: Izdatielstvo Iskusstvo.

Ferro, M. (1982). Affiches et imageries russes 1914-1921. Musée des Deux Guerres Mondiales. Paris: BDIC.

Kenez, P. (1985). The Birth of the Propaganda in State. Soviet methods of mass mobilization (1917-1929). Cambridge: Cambridge University Press.

Ivanov, V. (1980). Kak sozdaietsia plakat, v pomoch khudojniku-oformitielno, Izdatelstvo plakat, Moscú.

Le Bourgeois, J. (2007). Les affiches de propagande soviétique de 1917 a 1991, l'affiche de propagande, miroir de l'histoire, reflet des mentalités. Tesis de doctorado en Historia Contemporánea, Université de Caen Normandie, Francia.

Polonski, V. (1925). Ruski revoliutsioni plakat, Moscú.

Semenoff-Tian-Chansky, I. (1993). Le pinceau, la faucille et le marteau, les peintres et le pouvoir en Union soviétique de 1953 à 1989. Paris: Institut des Etudes slaves.

\section{Fuentes de afiches}

Museo Central de las Fuerzas Armadas Rusas, calle Sovietskoë, Moscú. Fondo de 90 mil afiches militares. Archivo Estatal Ruso de Literatura y Arte (RGALI), edificio 2 y 3, calle Vyborgskaïa, 125212, Moscú. 400 mil afiches de propaganda civil, desde 1915.

Biblioteca Nacional Rusa (Ilamada Biblioteca Lenin), 3/5 calle Vozdvizhenka, 101000, Moscú. 700 mil afiches de propaganda civil desde 1918.

Museo de Historia Contemporánea de la BDIC, Hotel National des Invalides, 129 calle Grenelle, 75007 París. Fondo de 1500 afiches de propaganda soviética de los cuales 600 son de la Perestroika. 